Revue

Revue de l'histoire des religions

de Ihistoire des religions

$3 \mid 2020$

Varia

\title{
Monica MARTINAT, 773 Vies, itinéraires de convertis au
} $\mathrm{XVII}$ siècle

Lyon, Presses Universitaires de Lyon («Faits de religion », 4), 2018

\section{Antoine Roullet}

\section{OpenEdition}

\section{Journals}

Édition électronique

URL : https://journals.openedition.org/rhr/10712

DOI : $10.4000 /$ rhr. 10712

ISSN : 2105-2573

Éditeur

Armand Colin

Édition imprimée

Date de publication : 1 septembre 2020

Pagination : 472-475

ISBN : 978-2-200-93327-2

ISSN : 0035-1423

Référence électronique

Antoine Roullet, "Monica Martinat, 773 Vies, itinéraires de convertis au xvIle siècle », Revue de l'histoire des religions [En ligne], 3 | 2020, mis en ligne le 01 janvier 2021, consulté le 06 janvier 2023. URL : http:// journals.openedition.org/rhr/10712 ; DOI : https://doi.org/10.4000/rhr.10712

Ce document a été généré automatiquement le 6 janvier 2023

Tous droits réservés 


\title{
Monica MARTINAT, 773 Vies, itinéraires de convertis au XVII siècle
}

Lyon, Presses Universitaires de Lyon («Faits de religion », 4), 2018

\author{
Antoine Roullet
}

\section{RÉFÉRENCE}

Monica MARTINAT, 773 Vies, itinéraires de convertis au XVII ${ }^{e}$ siècle, Lyon, Presses

Universitaires de Lyon ("Faits de religion », 4), 2018, 242 p., 23,5 cm, $20 €$, ISBN

978-27297-0936-5.

1 Cet ouvrage s'intéresse aux convertis au catholicisme à Lyon dans la seconde moitié du $\mathrm{XVII}^{\mathrm{e}}$ siècle. La recherche est principalement menée grâce aux registres des abjurations de la Compagnie de la Propagation de la Foi, conservés aux archives départementales du Rhône, et à une reconstitution de la population protestante lyonnaise à partir des archives notariées et des registres paroissiaux. Sans prendre exclusivement la forme d'une prosopographie qui risquerait d'effacer la complexité et la grande variété des parcours de convertis et de les réifier dans une catégorie douteuse, l'ouvrage juxtapose, compare, pèse des « itinéraires de conversion » du protestantisme au catholicisme. Les abjurants, qui ont tous en commun de traverser une « crise » de quelque nature que ce soit, sont majoritairement des femmes, surtout chez les plus jeunes, dans un état, transitoire ou durable, de faiblesse économique. Monica Martinat identifie deux profils majeurs : les migrants sans liens apparents avec la communauté réformée locale et les membres de l'Église réformée lyonnaise qui changent de confession. Cette opposition organise le plan de l'ouvrage, qui présente d'abord une vue d'ensemble, puis analyse dans deux séries de chapitres consécutifs chacun de ces cas, avant de rassembler ses apports historiographiques dans deux chapitres conclusifs.

2 Les abjurants étrangers - $40 \%$ des convertis étudiés par l'auteur -, cible privilégiée de la Compagnie, ont le plus souvent quitté Genève à cause des difficultés économiques de la ville et du manque de solidarité des Églises genevoises. Ils sont jeunes, souvent veufs 
ou veuves, et viennent du textile. La Compagnie leur apporte un soutien matériel, qui n'est jamais source d'enrichissement, mais elle leur permet de s'intégrer dans un nouveau réseau, catholique et lyonnais, beaucoup plus vaste, puisque à compter de la mi-XVII ${ }^{e}$ siècle, Lyon, qui avait été l'un des épicentres de la Réforme française, ne compte plus qu'un pour cent de réformés. Poussés à émigrer par un prosélytisme catholique de plus en plus visible à Genève après les années 1670, beaucoup arrivent à Lyon avec un "projet de conversion ». Les convertis locaux sont quant à eux délaissés par la Compagnie, surtout appliquée à creuser un fossé autour de la communauté «huguenote» en la coupant de l'extérieur. Très attachée à mettre en évidence la diversité des situations par une succession d'études de cas, l'auteur relie néanmoins le développement de ces conversions de locaux à trois facteurs, qu'il faut articuler les uns aux autres : les difficultés économiques, la pression du pouvoir monarchique - qui se fait de plus en plus ressentir après les années 1670 -, et les recompositions internes de la communauté protestante lyonnaise, rassemblant en théorie tous les réformés de la ville mais en réalité organisée de plus en plus autour des luttes de pouvoir d'une élite qui s'est fermée et resserrée. Le relâchement et le resserrement de la solidarité confessionnelle qui s'ensuivent facilitent le passage à la religion catholique, qui offre davantage de perspectives. Ainsi, les libraires protestants ne peuvent par exemple choisir des parrains dans la librairie et entretenir un réseau professionnel que lorsqu'ils se convertissent, car le monde de la librairie protestant est désormais trop restreint.

3 La grande force de l'ouvrage est d'être souvent une discussion à ciel ouvert, une "construction dialogique en devenir", ce qui lui donne parfois des allures de conversion historiographique, notamment dans les deux derniers chapitres. L'étude tente d'articuler deux champs problématiques qui, mis l'un face à l'autre, paraissent souvent contradictoires. Le travail s'organise en effet autour d'une double tension, d'une part entre histoire sociale et histoire religieuse, et d'autre part au sein de l'histoire sociale autour de la représentativité ou non de la micro-histoire et de la marge de liberté dont disposaient les acteurs sous l'Ancien Régime. C'est une manière de s'attaquer implicitement à deux idoles de la modernité, l'autonomie de l'individu et celle du religieux, projet salutaire mais toujours difficile à mener tant ces dichotomies formatent aujourd'hui nos institutions et nos modes de pensée. Le grand mérite de l'ouvrage est d'expliciter le problème et d'y chercher des solutions en refusant ce cadre de pensée sans pour autant - et c'est normal - parvenir forcément à s'en affranchir. Le cadre de l'étude est explicitement choisi pour faire ressortir la fluidité et la variété des situations que l'auteur met bien en évidence, en multipliant les études de cas et en mobilisant la situation économique des acteurs, la structuration de leur parenté, leur position sociale, de sorte qu'au-delà d'une mise en contexte très générale, il est difficile de dégager des trajectoires-types de convertis et de les historiciser dans le détail. Entre la vision globale et difficilement interprétable de l'approche statistique et la myopie des études de cas, l'ouvrage peine à dégager une voie moyenne, ce qui est moins sa faiblesse que le fruit de son honnêteté et la conséquence de ses choix méthodologiques qui, toujours, tentent à la fois de souligner les différents possibles s'offrant aux acteurs tout en rappelant que cet horizon est limité. Mais le véritable propos du livre, plutôt que d'engager une discussion insoluble sur la rigidité des sociétés et des corps d'Ancien Régime, est de chercher un moyen d'articuler sans contradiction les enjeux socioéconomiques et les enjeux religieux. Face à l'histoire religieuse, en particulier face à une historiographie dense sur le thème de la conversion et qui insiste sur la dimension de rupture spirituelle chez le converti, M. Martinat rappelle qu'on ne peut pas (ou alors 
très exceptionnellement) faire entendre la voix des convertis, et que le discours, religieux ou spirituel, qui justifie la conversion est loin d'épuiser son sens. Renonçant à la primauté implicite du religieux dans l'explication et convoquant une histoire sociale, populaire et démocratique malheureusement en perte de vitesse, l'ouvrage participe d'abord, parfois à son corps défendant, à une forme de retour de balancier qui marginalise le religieux. La conversion, que l'auteur s'attache à bien distinguer de l'abjuration, n'est qu'exceptionnellement une rupture, même quand l'abjuration est mise en scène pour le bien dans la guerre confessionnelle menée par les autorités catholiques: elle est parfois déjà préparée par une indifférence religieuse certes difficile à documenter, elle ne coupe pas véritablement le converti de sa famille, de ses anciennes solidarités auxquelles il peut revenir. Elle ne constitue pas nécessairement une rupture identitaire. La conversion peut être un choix facile, elle offre des solutions et permet de s'intégrer dans la cité, particulièrement quand il s'agit de passer d'une confession chrétienne à une autre alors que les oppositions théologiques, aux yeux des acteurs, ont une importance limitée. En surévaluant le côté religieux et intime de l'abjuration comme on le fait habituellement, on force l'opposition entre motivations intimes et motifs matériels de la conversion, alors que cette opposition n'a pas vraiment lieu d'être et charrie des anachronismes. La légèreté, selon l'auteur, avec laquelle nombre d'acteurs prennent la conversion, ainsi que la perméabilité des frontières religieuses, ouvrent en effet une brèche heureuse dans la rhétorique de la confessionnalisation qui corsète l'historiographie de l'époque moderne et explique par exemple à quel point l'historiographie se focalise sur la "résistance» des minorités religieuses, un thème dont Monica Martinat montre qu'il rend mal compte des logiques à l'œuvre. Toutefois, minimiser le religieux, ce n'est pas l'escamoter et l'auteur annonce à plusieurs reprises sa volonté de ne pas ensevelir le religieux dans le social, même si souvent ses conclusions y incitent. C'est plutôt une reconfiguration de celui-ci que l'ouvrage appelle de ses vœux, dans la lignée des travaux de Nathalie Rothman. L'appartenance à une communauté religieuse étant sous l'Ancien Régime l'une des inscriptions fondamentales qui accompagnent la vie spirituelle et familiale, en faire d'abord une affaire personnelle et intime trahit surtout une vision contemporaine du problème. Il reste que s'il est vraiment impossible d'écouter la voix des convertis, cet appel à sauver malgré tout le religieux tient du vœu pieux face à la démonstration implacable du pragmatisme matériel des acteurs.

\section{AUTEURS}

\section{ANTOINE ROULLET}

CNRS, Centre de recherches historiques. 